\title{
Do Women Get Fewer Votes? No.
}

\author{
SEMra SEVI, Université de Montréal ${ }^{*}$ \\ VINCENT AREL-BUNDOCK, Université de Montréal \\ ANDRÉ BLAIS, Université de Montréal
}

\begin{abstract}
We study data on the gender of over 21,000 unique candidates in all Canadian federal elections since 1921, when the first women ran for seats in Parliament. This large dataset allows us to compute precise estimates of the difference in the electoral fortunes of men and women candidates. When accounting for party effects and time trends, we find that the difference between the vote shares of men and women is substantively negligible ( \pm 0.5 percentage point). This gender gap was larger in the $1920 \mathrm{~s}$ ( \pm 2.5 percentage points), but it is now statistically indistinguishable from zero. Our results have important normative implications: Political parties should recruit and promote more women candidates, because they remain underrepresented in Canadian politics, and because they do not suffer from a substantial electoral penalty.
\end{abstract}

\section{INTRODUCTION}

This article addresses a simple, but fundamental question: Do women political candidates get fewer votes than their male counterparts? The answer to this question matters a great deal, because women are under-represented in both legislatures and in the pool of candidates who run for office. If women receive fewer votes than men, political parties may be reluctant to recruit and promote the former.

The electoral fortunes of women are especially important given all that we know about the effect of gender representation in legislatures. Indeed, research suggests that women legislators have different values, policy preferences, and priorities (Lovenduski and Norris 2003; Welch 1985; TaylorRobinson and Heath 2003; Ford and Dolan 1995; Saint-Germain 1989; Swers 1998). As a result, legislatures with more women are more likely to adopt policies that are consistent with such values and priorities (Thomas 1991; Swers 2001; Berkman and O'Connor 1993). Furthermore, the underrepresentation of women has long-term consequences for the persistent gender gap in political knowledge (Dassonneville and McAllister, 2018).

What does prior research tell us about the effect of gender on electoral performance? As far as we can tell, only two previous studies have addressed this question in the Canadian context. The first is Hunter and Denton (1984), which compares the electoral performance of men and women candidates in the 1979 and 1980 Canadian general elections. They first report that "female candidates received about 53 per cent as many votes as did males in 1979, and about 44 per cent as many votes in

\footnotetext{
*Corresponding author: semra.sevi@umontreal.ca
} 
1980" (p.399). But those differences disappear when they control for incumbency, competitiveness, and the party of the candidate. Hunter and Denton thus conclude that there is no evidence that female candidates do worse than men.

Twenty years later, Black and Erickson (2003) examine the same question in the case of the 1993 Canadian federal election. When data for this election are analyzed without statistical controls, women get fewer votes. However, the gap disappears when incumbency, competitiveness, and party are taken into account. Black and Erickson even find a small positive effect, with women candidates receiving one percentage point more votes. The authors thus conclude that "no evidence was found to support the hypothesis of voter bias against women" (p.96) and even argue "for more in-depth investigations into the basis of the female vote advantage" (p.96). ${ }^{1}$

In this paper, we improve upon prior efforts by considerably expanding the scope of investigation: We study data on the gender of over 21,000 candidates in all Canadian general elections since 1921, when women first ran for seats in Parliament. This large dataset allows us to compute precise estimates (i.e., with small standard errors) of the difference in the electoral fortunes of men and women candidates. When accounting for party effects and time trends, we find that the difference between the vote shares of men and women is substantively negligible ( \pm 0.5 percentage point).

The broad coverage of our dataset also allows us to assess how the electoral fortunes of men and women change over time. We find that the gender gap in vote share was larger in the $1920 \mathrm{~s}( \pm 2.5$ percentage points), but that it is now statistically indistinguishable from zero.

Our results have important normative implications: Political parties should recruit and promote more women candidates, because they remain under-represented in Canadian politics, and because they do not suffer from a substantial electoral penalty.

\section{WOMEN ARE UNDER-REPRESENTED IN CANADIAN POLITICS}

Our comprehensive data on the gender of all candidates for office in Canadian federal elections allows an unparalleled look at the representation of women over time. Figure 1 shows that despite progress in recent decades, the problem of under-representation persists. In the latest general elections, about $30 \%$ of candidates were women, and about $25 \%$ of elected representatives were women.

Some (cynical) election-focused party organizers might ask: Would increasing the share of women candidates be electorally costly?

To answer this question, we estimate the relationship between the gender of candidates and the vote share that they received since 1921, when the first five women candidates ran in Canadian general elections (Harriet S. Dick, Rose Mary Louise Henderson, Elizabeth Bethune Kiely, Agnes Campbell Macphail, and Harriet Dunlop Prenter). 
Figure 1: Women are under-represented in Canadian general elections.
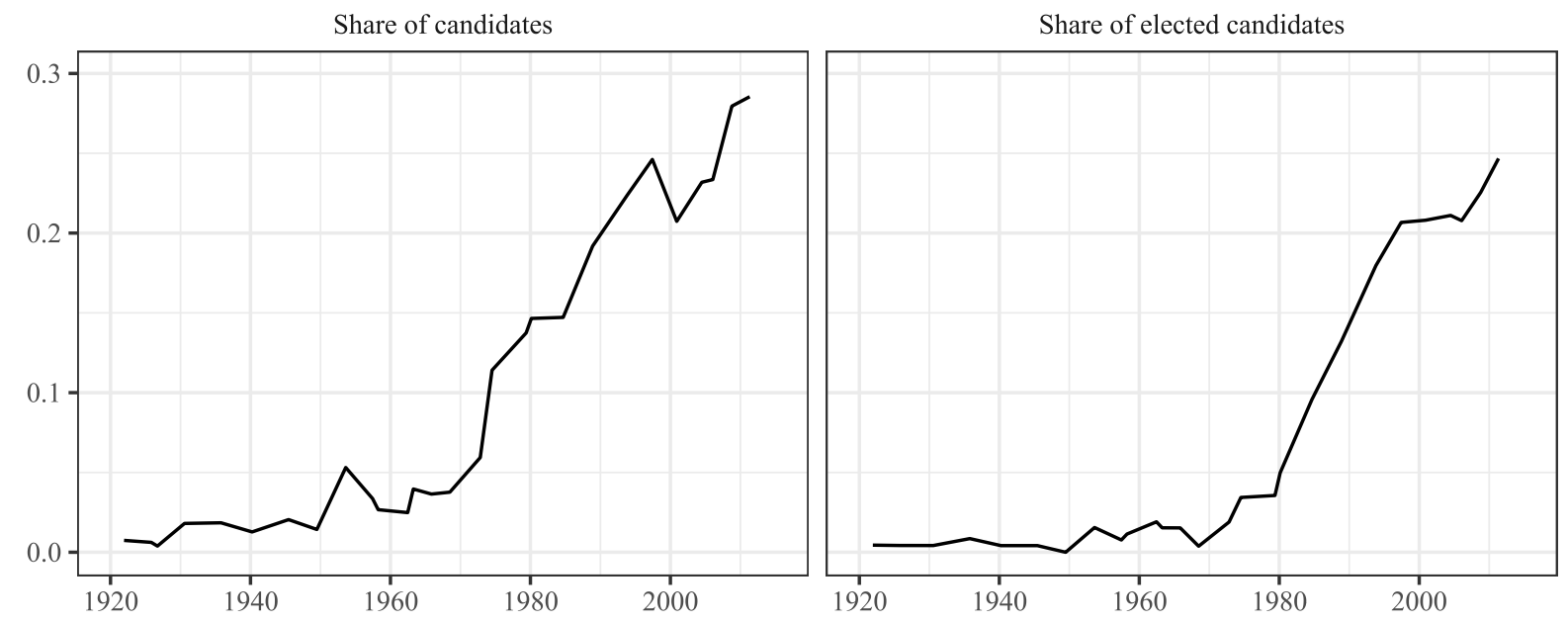

\section{THE GENDER GAP IN Vote SHARE IS Very SMALL}

We use data on election results published by the Library of Parliament, ${ }^{2}$ which cover all 29 Canadian general elections since 1921, when the first women ran for seats at the federal level. This dataset includes observations for over 21,000 unique individuals who contested a federal seat. ${ }^{3}$ We coded the gender of each of those individuals manually.

\section{Baseline estimate of the gender gap}

To begin, we estimate the simplest possible regression model, focusing solely on the bivariate association between a candidate's vote share and her gender:

$$
V_{\text {pre }}=\beta_{1} W_{\text {pre }}+\alpha+\epsilon_{\text {pre }}
$$

where $V_{p r e}$ is the vote share of party $p$, in riding $r$, in election $e ; W_{\text {pre }}$ is a binary variable which equals 1 if party $p$ 's candidate is a woman and 0 otherwise; $\alpha$ is a constant; and $\epsilon_{p r e}$ is a disturbance term. ${ }^{4}$

The first column of Table 1 shows that, on average, the vote share of women candidates is about 8 percentage points lower than the vote share of men candidates.

However, this should not lead us to conclude that there is a large electoral penalty for women. As we show below, this bivariate relationship is spurious, because it is confounded by time, party, and riding effects. 
Table 1: The gender gap in Canadian federal general elections. Ordinary Least Squares regression models with party vote share as dependent variable

\begin{tabular}{|c|c|c|c|c|c|}
\hline & $(1)$ & $(2)$ & (3) & $(4)$ & (5) \\
\hline \multirow[t]{2}{*}{ Woman } & $-8.4^{\star * \star}$ & $-4.0^{\star * \star}$ & $-0.5^{\star}$ & $-0.5^{\star \star \star}$ & $-0.4^{\star \star \star x}$ \\
\hline & $(0.3)$ & $(0.3)$ & $(0.2)$ & $(0.1)$ & $(0.1)$ \\
\hline \multirow[t]{2}{*}{ Vote share lag } & & & & $0.4^{\star \star \star}$ & $0.3^{\star * \star}$ \\
\hline & & & & $(0.0)$ & $(0.0)$ \\
\hline \multirow[t]{2}{*}{ Party performance } & & & & $0.7^{\star * \star}$ & $0.7^{\star * *}$ \\
\hline & & & & $(0.0)$ & $(0.0)$ \\
\hline \multirow[t]{2}{*}{ Incumbent } & & & & & $6.8^{\star * \star}$ \\
\hline & & & & & $(0.2)$ \\
\hline \multirow[t]{2}{*}{ Distance from contention } & & & & & $-0.0^{\star \star}$ \\
\hline & & & & & $(0.0)$ \\
\hline \multirow[t]{2}{*}{ Constant } & $24.4^{* * *}$ & $37.8^{\star * *}$ & $29.1^{\star * *}$ & $-1.2^{\star \star \star}$ & 0.3 \\
\hline & $(0.1)$ & $(0.8)$ & $(1.1)$ & $(0.1)$ & $(0.3)$ \\
\hline $\mathrm{R} 2$ & 0.02 & 0.13 & 0.11 & 0.86 & 0.87 \\
\hline FE Party-Riding & No & No & Yes & No & No \\
\hline FE Election & No & Yes & Yes & No & No \\
\hline $\mathrm{N}$ & 33981 & 33981 & 33981 & 23903 & 23903 \\
\hline
\end{tabular}

Time trends

Figure 2 shows that the average number of candidates per riding increases over time in Canadian elections. As a consequence, the average vote share decreases. Since the number of women candidates follows a parallel time trend, the bivariate association between vote share and gender that we reported above is confounded.

To control for time trends, we estimate a new model:

$$
V_{\text {pre }}=\beta_{1} W_{\text {pre }}+\alpha_{e}+\epsilon_{\text {pre }}
$$

where $\alpha_{e}$ represents time-varying intercepts (i.e., election fixed effects). The $\alpha_{e}$ dummy variables control for time trends that affect the country as a whole, as well as for any election-specific shock that affects every party in every riding in the same way throughout Canada. 
Column 2 of Table 1 shows that this simple control for country-level time trends leads to a dramatic reduction in the size of the estimated gender gap, going from 8 to 4 percentage points.

Figure 2: In Canadian general elections, the average number of candidates increases and the average vote share decreases over time.
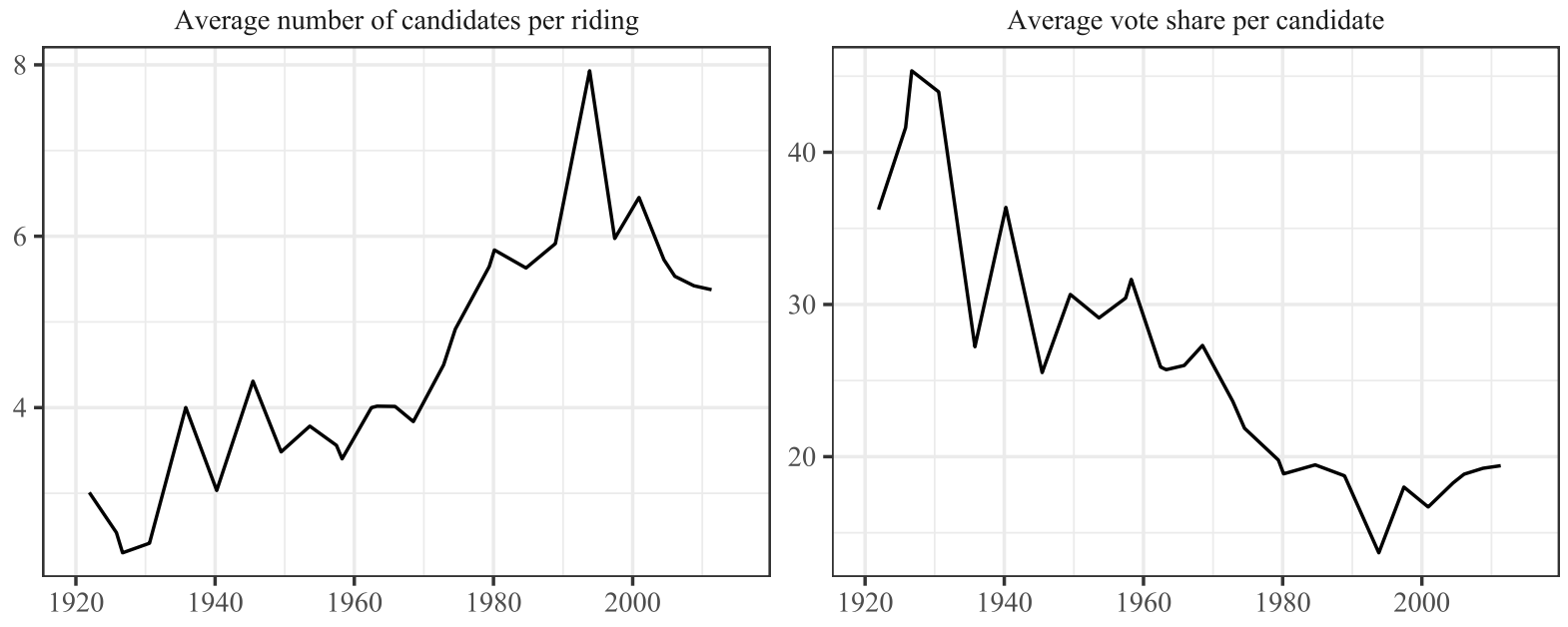

\section{Party and riding effects}

Another confounder is party popularity. If women tend to represent smaller parties, then the difference in vote shares between men and women might be explained by party effects. Table 2 shows that this is indeed the case: Some third parties (e.g., New Democratic Party, Green Party of Canada) have had more success than major parties in the House of Commons at recruiting and promoting women candidates. This is likely to reflect the facts that leftist parties are more prone to encourage women to run for office (Erickson 1997; Tremblay 1998; Caul 2001; Cheng and Tavits 2011) and that most third parties in federal elections have been on the left. ${ }^{5}$ 
Table 2: Gender representation in Canadian political parties (\%). All federal elections, 1993-2015.

\begin{tabular}{lll}
\hline Party & Average party vote share & Share of women candidates \\
\hline Bloc Québécois & 37 & 25 \\
Conservative Party of Canada & 35 & 17 \\
Liberal & 35 & 27 \\
Reform Party of Canada & 26 & 10 \\
Canadian Alliance & 25 & 11 \\
New Democratic Party & 17 & 36 \\
Progressive Conservative & 16 & 18 \\
Green Party of Canada & 4 & 29 \\
\hline
\end{tabular}

Another potential problem relates to gender bias in the geographic distribution of women candidates. If a party selects women to run in districts where it is less competitive, that discrimination could exaggerate the estimated gender penalty in electoral results.

We estimate two models to account for party and riding effects:

$$
\begin{array}{r}
V_{p r e}=\beta_{1} W_{p r e}+\alpha_{e}+\lambda_{p r}+\epsilon_{\text {pre }} \\
V_{\text {pre }}=\beta_{1} W_{\text {pre }}+\beta_{2} V_{\text {pre }-1}+\beta_{3} \bar{V}_{p k e}+\alpha+\epsilon_{\text {pre }}
\end{array}
$$

Model 3 adds a dummy variable for each party-riding combination $\left(\lambda_{p r}\right)$. These fixed effects control for the facts that some parties are less popular than others, and that a party's popularity varies from riding to riding. These are precisely the two threats to inference that arise when a woman runs for a third party or in a riding where her party is not competitive.

An alternative way to account for the same phenomena is shown in Equation 4, where we control for the party's vote share in the last election $\left(V_{\text {pre-1 }}\right)$, and for the average vote share that each party $p$ obtains in each province $k$ during election $e\left(\bar{V}_{p k e}\right)$.

Columns 3 and 4 of Table 1 show results from those two models. Whereas the simple bivariate analysis pointed to a large gap in the electoral fortunes of men and women, controlling for time, party, and riding effects suggests that the difference is actually quite small: About half a percentage point.

It is important to emphasize that since our dataset is very large, the association between gender and vote shares is very precisely estimated. Our empirical analysis can thus show that the gender gap is substantively small, even if it is statistically significant.

\section{DOES THE GENDER GAP DECREASE OVER TIME?}

If the Canadian electorate is growing more attuned to the rights of women, the gender gap should decrease over time. 
In the left panel of Figure 3, we plot the average vote share of men and women candidates over time (LOESS curves). For much of the period, there is a large observable gap between the electoral results of men and women candidates, but that gap has all but disappeared today. However, as we explained above, a simple bivariate analysis like this one can exaggerate the difference between men and women, because it ignores time, party, and riding effects.

To account for these factors, we replicate the model in Equation 4, and interact the Woman indicator with a continuous Year variable:

$$
V_{\text {pre }}=\beta_{1} W_{\text {pre }}+\beta_{2} Y_{e}+\beta_{3} W_{\text {pre }} Y_{e}+\beta_{4} V_{\text {pre-1 }}+\beta_{5} \bar{V}_{p k e}+\alpha+\epsilon_{\text {pre }}
$$

The right panel of Figure 3 shows the estimated marginal effect of gender on vote share that we estimated using Equation $5\left(\partial V_{\text {pre }} / \partial W_{\text {pre }}=\beta_{1}+\beta_{3} Y_{e}\right)$. We find that in the 1920s, the (adjusted) gender gap in vote share was about 2.5 points. Today, it is much smaller and statistically indistinguishable from zero.

Figure 3: The gender gap in electoral performance decreases over time.
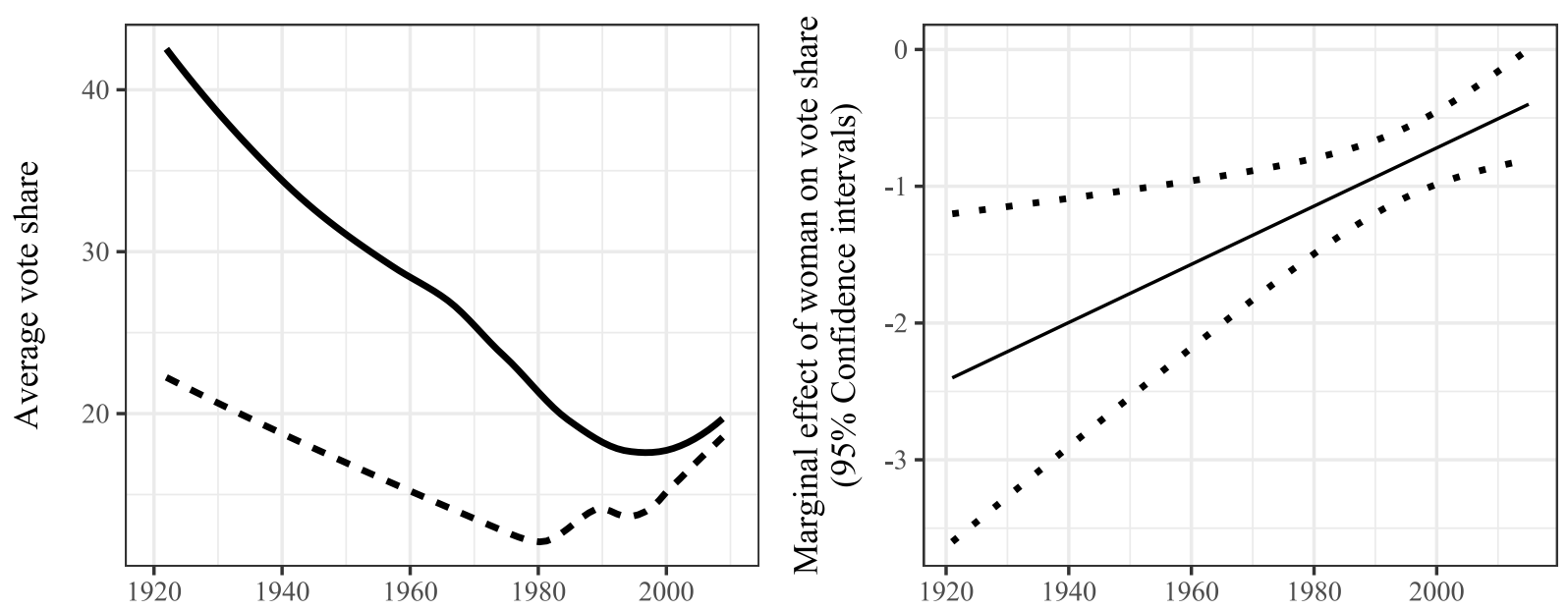

- Men - - Women

\section{ROBUSTNESS}

We took several steps to ensure that the results reported above are robust. First, we estimated a new model with control variables for whether a party is the district-level incumbent. That model also controls for whether a party is a serious contender in a district (i.e., the distance between that party's vote share and the winner's vote share in the previous election). The results in column 5 of Table 1 are not qualitatively different from the rest.

Second, we estimated a version of Model 4 with different Woman coefficients for each province. Whereas we found some differences between provinces (e.g., the Woman coefficient is positive in Prince Edward Island, but negative in Newfoundland), there is no obvious regional clustering, and most of the estimated Woman coefficients hover around zero (see Figure 4 in 
appendix). Overall, the finding that women do not suffer from a substantial electoral penalty seems to hold across much of the country.

Finally, we re-estimated our core time-varying specification using a logit model with a binary dependent variable which equals one when the candidate was elected and zero otherwise. Again, our main conclusions are unchanged (see Figure 5 in appendix).

\section{INTERPRETATION AND CAVEATS}

To conduct the analyses reported in this paper, we manually coded the gender of over 21,000 unique candidates in Canadian federal elections, and built a dataset covering all general elections in the 19212015 period. We used this comprehensive data to estimate the gap in vote shares between men and women candidates. Importantly, the large size of our database allows us to offer precise estimates of the gap in question.

After controlling for country-level time trends, we estimate that the difference in the vote shares of men and women candidates is about four percentage points. Almost all of that difference can be linked to the fact that women tend to run for relatively unpopular parties. When we control for time and party effects, the gap between men and women all but disappears. Indeed, our preferred regression models suggest that this gap is very small ( \pm 0.5 percentage point). We also found evidence that the gender gap was higher decades ago, but that it gradually disappeared over time.

Throughout the text, we were careful to interpret our results in descriptive rather than causal terms. This is because some of the formal conditions required for causal identification are quite stringent and may be violated here. One important concern is that unmeasured candidate-level characteristics could be related to both the dependent variable and the probability that a person will be nominated by her party.

For instance, if structural discrimination makes the path to nomination more arduous for women, then the typical woman candidate may be of higher "quality" than the typical man candidate. If candidate "quality" is positively associated to vote shares, our estimates of the Woman coefficient could be biased toward zero. In other words, if women candidates tend to be "better" than men candidates in some unmeasurable way, the lack of a gender gap in vote shares could actually constitute evidence of electoral discrimination against women. ${ }^{6}$ Researchers could improve on our work by expanding our database to include indicators of candidate quality. 


\section{APPENDIX}

Figure 4: Model 4 with province-specific Woman coefficients. 95\% confidence intervals with Bonferroni correction.

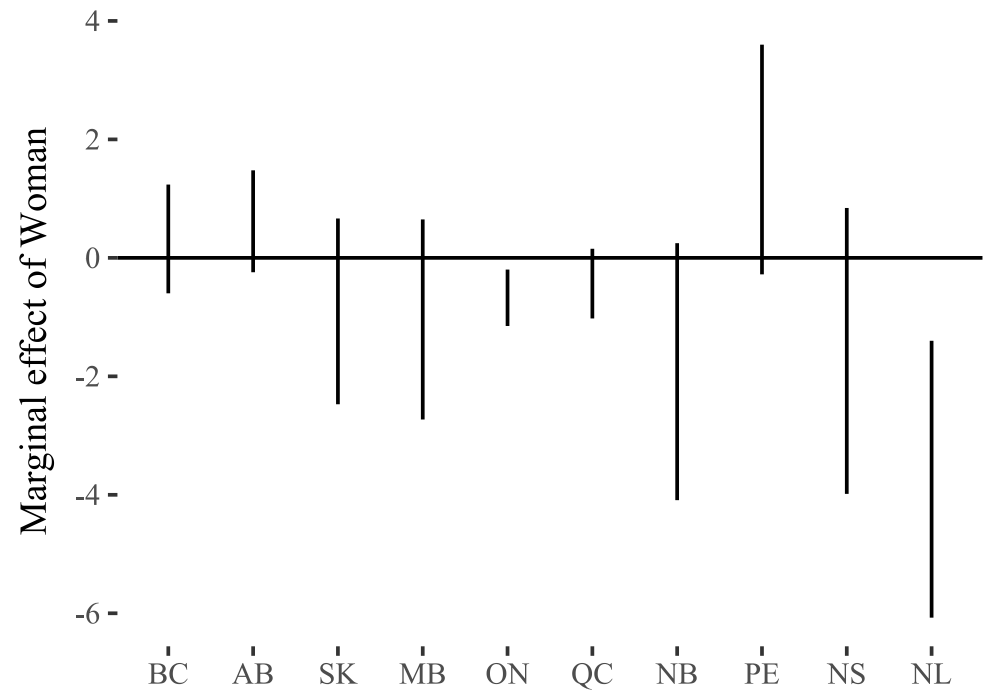

Figure 5: The gender gap in electoral performance decreases over time.
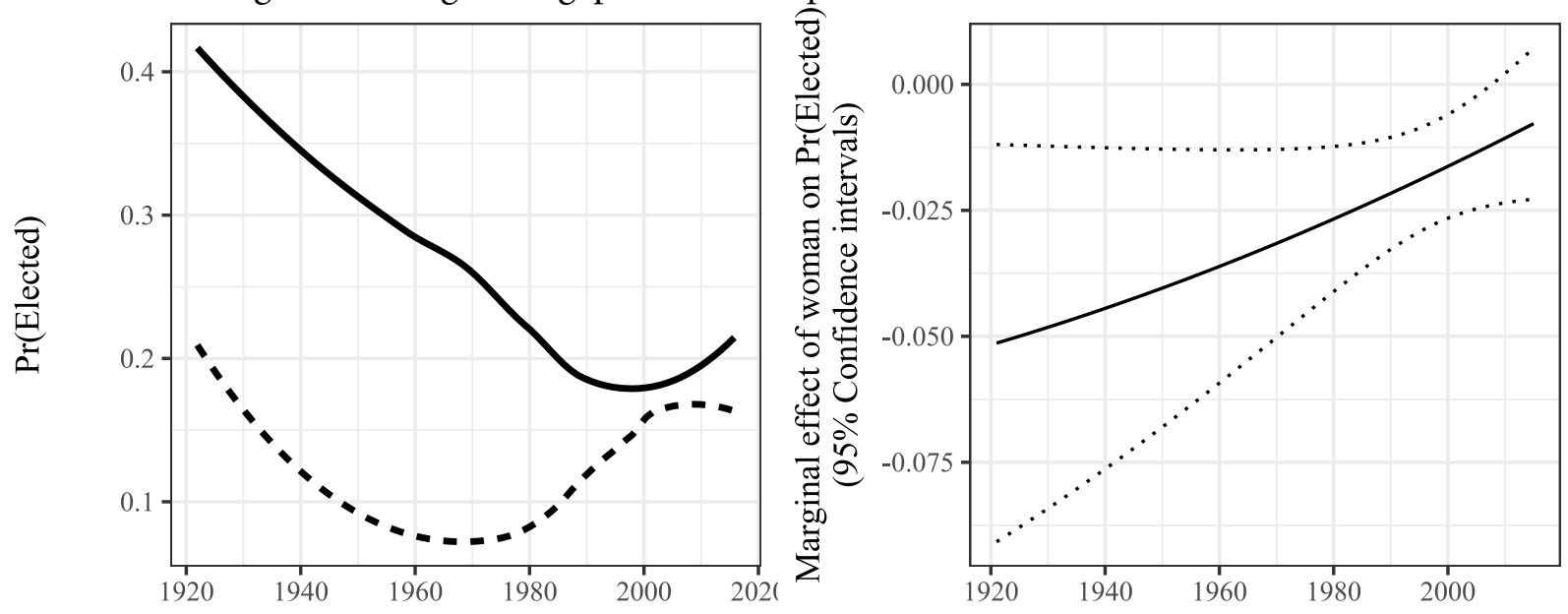

- Men = - Women 


\section{NOTES}

${ }^{1}$ The results in those two Canadian studies are broadly consistent with research using data from other countries. See Lawless and Pearson 2008; Welch and Studlar 1988; Zipp and Plutzer 1985; Darcy and Schramm 1977; McElroy and Marsh 2010; Dolan 2004; King and Matland 2002.

${ }^{2}$ https://lop.parl.ca/About/Parliament/FederalRidingsHistory/HFER.asp

${ }^{3}$ The candidate names recorded by the Library of Parliament are sometimes inconsistent from election to election. To follow candidates over time, we assigned each of them a unique identification number.

${ }^{4}$ Formally, our unit of analysis is not the candidate itself, but rather party/riding/election combinations. Because parties often present the same candidates in several elections, the number of observations in our dataset is larger than the number of unique candidates in the database. In the rare circumstances where a party presents more than one candidate in the same riding, $V_{\text {pre }}$ is the sum of vote shares, and $W_{\text {pre }}$ is the mean of the woman dummy, taken over all the candidates of party $p$ in riding $r$ for election $e$.

${ }^{5}$ On the selection of women to lead political parties in Canada, see Thomas (2018). On the election of women in provincial elections, see Matland and Studlar (1998). On women candidates in a corrupt environment, see Erlich (2018).

${ }^{6}$ The evidence for this argument is mixed. On the one hand, Fulton $(2012,2014)$ shows that, in some statistical analyses, controlling for the valence/quality of candidates produces non-zero estimates of the gap between men and women's vote share. On the other, Black and Erickson (2003) use a candidate survey to derive measures of "candidate quality," and they find that controlling for quality does not affect the overall results. Unfortunately, measuring the quality of all 21,000 candidates in our database was not possible due to time, resource, and data availability constraints. 


\section{REFERENCES}

Berkman, Michael B. and Robert E. O'Connor. 1993. "Do Women Legislators Matter? Female Legislators and State Abortion Policy." American Politics Quarterly 21(1): 102-124.

Black, J.H and L. Erickson. 2003. "Women candidates and voter bias: do women politicians need to be better?" Electoral Studies 22: 81-100.

Caul, Miki. 2001. "Political Parties and the Adoption of Candidate Gender Quotas: A Cross-National Analysis." The Journal of Politics 63(4): 1214-1229.

Cheng, Christine and Margit Tavits. 2011. "Informal Influences in Selecting Female Political Candidates." Political Research Quarterly 64(2): 460-471.

Dassonneville, Ruth and Ian McAllister. 2018. "Gender, Political Knowledge and Descriptive Representation: The Impact of Long-Term Socialization." American Journal of Political Science 62(2): 249-265.

Darcy R. and Sarah Slavin Schramm. 1977. "When Women Run Against Men." Public Opinion Quarterly 41(1): 1า-12.

Dolan, Kathleen A. 2004. Voting for Women: how the public evaluates women candidates. Westview Press.

Erickson, Lynda. 1997. "Might More Women Make a Difference? Gender, Party and Ideology among Canada’s Parliamentary Candidates." Canadian Journal of Political Science 30(4): 663-688.

Erlich, Aaron. 2018 "Evaluating Women Candidates in a Corrupt Environment with Low Levels of Women's Representation” Montreal: Mimeo.

Ford, Lynne E. and Kathleen Dolan. 1995. "The Politics of Women State Legislators: a south/ nonsouth comparison." Southeastern Political Review 23(2): 333-348.

Fulton, Sarah A. 2012. "Running Backwards and in High Heels: The Gendered Quality Gap and Incumbent Electoral Studies." Political Research Quarterly 65(2): 303-314.

Fulton, Sarah A. 2014. "When Gender Matters: Macro-dynamics and Micro-mechanisms." Political Behavior 36(3): 605-630.

Hunter, Alfred A. and Margaret A. Denton. 1984. “Do female candidates 'lose votes'?: the experience of female candidates in the 1979 and 1980 Canadian general election." Canadian Review of Sociology 21(4): 395-406.

King, David C. and Richard E. Matland. 2002. "Sex and the Grand Old Party: An Experimental Investigation of the Effect of Candidate Sex on Support for a Republican Candidate." American Politics Research 31(6): 595-612.

Lawless, Jennifer L. and Kathryn Pearson. 2008. "The Primary Reason for Women's Underrepresentation? Reevaluating the Conventional Wisdom." The Journal of Politics 70(1): 67-82. 
Lovenduski, Joni and Pippa Norris. 2003. "Westminster Women: the Politics of Presence." Political Studies 51: 84-102.

Matland, R.E. and Studlar, D.T., 1998. "Gender and the electoral opportunity structure in the Canadian provinces.” Political Research Quarterly, 51(1), pp.117-140.

McElroy, Gail and Michael Marsh. 2010. "Candidate Gender and Voter Choice: Analysis from a Multimember Preferential Voting System." Political Research Quarterly 63(4): 822-833.

Saint-Germain, Michelle A. 1989. "Does Their Difference Make a Difference? The Impact of Women on Public Policy in the Arizona Legislature." Social Science Quarterly 70(4): 956-968.

Swers, Michele L. 1998. “Are Women More Likely to Vote for Women's Issue Bills than Their Male Colleagues?" Legislative Studies Quarterly 23(3): 435-448.

Swers, Michele. 2001. "Understanding the Policy Impact of Electing Women: Evidence from Research on Congress and State Legislatures." Political Science and Politics 34(2): 217-220.

Taylor-Robinson, Michelle M. and Roseanne Michelle Heath. 2003. "Do Women Legislators Have Different Policy Priorities than Their Male Colleagues? A Critical Case Test." Women \& Politics 24(4): 77-101.

Thomas, Melanee. 2018. "In Crisis or Decline? Selecting Women to Lead Provincial Parties in Government.” Canadian Journal of Political Science 51(2) : 379-403.

Thomas, Sue. 1991. "The Impact of Women on State Legislative Policies." The Journal of Politics 53(4): 958-976.

Tremblay, Manon. 1998. "Do Female MPs Substantively Represent Women? A Study of Legislative Behaviour in Canada's 35th Parliament." Canadian Journal of Political Science 31(3): 435-465.

Welch, Susan. 1985. "Are Women More Liberal than Men in the U.S. Congress?" Legislative Studies Quarterly 10(1): 125-134.

Welch, Susan and Donley T. Studlar. 1988. “The Effects of Candidate Gender on Voting for Local Office in England." British Journal of Political Science 18(2): 273-281.

Zipp, John F. and Eric Plutzer. 1985. "Gender Differences in Voting for Female Candidates: Evidence From the 1982 Election." The Public Opinion Quarterly 49(2): 179-197. 